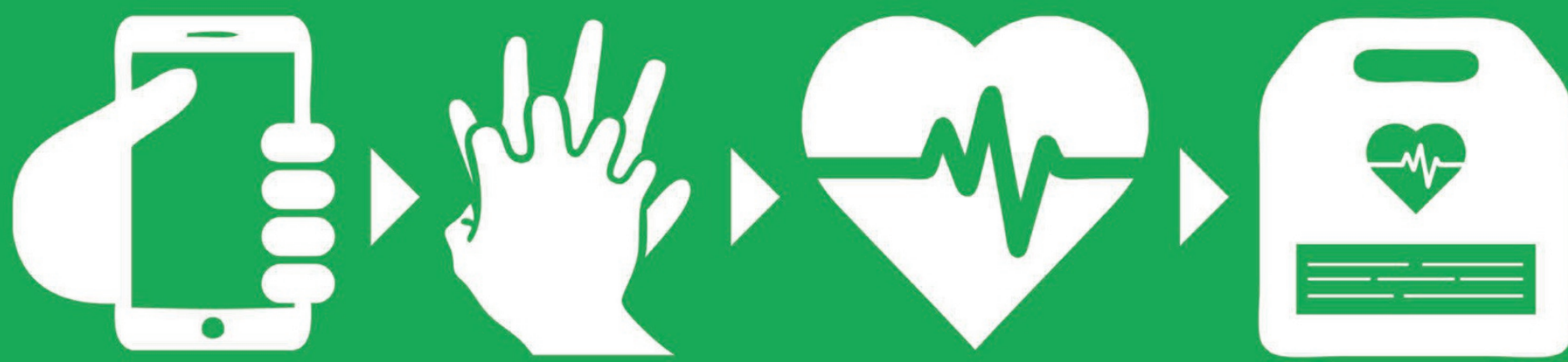

\title{
A guide to
}

How to save a life with

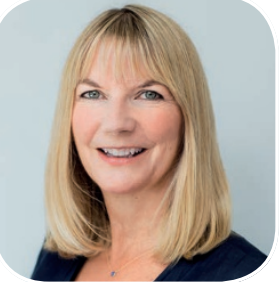

Emma Hammett of First Aid for Life outlines how to use a defibrillator in the event of a patient going into cardiac arrest. encouraged to have an AED on the premises. In the event of a cardiac arrest in a dental practice, when calling 999 for an ambulance, send a colleague to fetch the AED (and resuscitation equipment) whilst starting chest compressions. Each minute of delay to defibrillation reduces the probability of survival by $10 \%$.

Hundreds of people are alive today entirely due to the prompt and appropriate use of a defibrillator. AEDs are now easily accessible at numerous locations; train and tube stations, shopping centres, dental and GP practices, sports grounds, leisure centres... and are available for the general public to use. They can be semi-automatic (you still need to press the shock button when indicated) or fully automatic (the machine shocks automatically when a shock is advised).

Defibrillators are absolutely vital to be able to bring someone back following a cardiac arrest. CPR keeps the heart and brain full of oxygenated blood and acts as a life support machine; however, it is the AED that enables the heart to be shocked back into sinus rhythm. These two interventions together give the casualty the very best chance of survival.

One of the most high-profile cases surrounding defibrillators involved footballer Fabrice Muamba, who suffered a cardiac arrest in 2012. He was incredibly lucky that his
Tottenham Hotspur FC, at

White Hart Lane had both appropriately trained people and a defibrillator.

Fabrice Muamba required a total of 15 defibrillation shocks between his collapse and arriving at the London Chest Hospital (LCH). His heart was highly unstable and he repeatedly reverted back to a shockable rythm.

Any casualty is likely to remain in a highly unstable state and may well require further shocks - never be tempted to remove the defibrillator pads if the casualty appears to recover, as you may need the defibrillator again and you only have a limited number of pads

After arriving at hospital, it took a further 30 minutes of delivering shocks and medication to stabilise Fabrice. Despite undergoing CPR for an astonishing 80 minutes, Fabrice Muamba went on to make a full recovery and is now an ardent campaigner for the importance of the AED.

The sooner you recognise there is a problem, get help on the way, start CPR, use a defibrillator and then transfer the casualty to advanced medical care - the better the outcome.

\section{How a defibrillator works}

The defibrillator administers a shock to stop the heart. Enabling the heart's own system to reboot and hopefully restart in sinus rhythm. It should only be used when someone is unconscious and not breathing. 
The machine analyses the casualty's heart rhythm and will only allow a shock to be given if they are in a shockable rhythm. It is not possible to override this with an AED and if a shock is not advised you should continue to give CPR until the ambulance arrives.

Ensure the team are all competent and confident in performing the best possible CPR pushing down 5-6 cms on the centre of the chest at a rate of about 2 compressions per second and ensuring a release from pressure in between compressions - to enable the heart to refill.

\section{Shockable rhythms}

An AED will only allow you to administer a shock when someone is in ventricular fibrillation (VF) or ventricular tachycardia (VT).

VF - ventricular fibrillation (Figure 1) causes the casualty to become unconscious and stop breathing. VF is a shockable rhythm and if a defibrillator is used promptly on someone in VF there is a strong chance that stopping the heart with the shock will allow the heart to restart in a normal rhythm. The longer someone remains in VF the less likely it is that their heart will restart normally.

If an area of heart muscle is damaged due to a heart attack, the casualty may well survive, depending where the damage occurs and how much heart muscle is lost.

Because the heart has so many back-up systems, even if one of the pacemakers is damaged, the heart itself may still be able to generate sufficient electrical impulses to contract. The heart is an amazing organ comprising cells capable of independently generating impulses; the 2 pacemakers work together and act like the conductor of an orchestra initiating the correct impulses and ensuring that the heart beats to a fairly regular rhythm.

When an area of heart muscle is damaged it becomes unstable and often fires off its own impulses independently and this interferes with the co-ordinated rhythm generated by the pacemakers.

This misfiring affects the rhythm of the heart and causes it to become irregular. If the heart experiences a 'misfiring' beat at the point when the cells are re-charging, this can upset the whole system and the different cells fire independently of each other causing the heart to quiver erratically and chaotically. This is known as ventricular fibrillation and whilst the heart is shaking instead of pumping, it is incapable of effectively circulating the blood around the body.

VT - Ventricular tachycardia (Figure 2) is another shockable rhythm. The heart rate has become so fast that the chambers are incapable of refilling and so there is little or no blood being pumped around the body. If the casualty
Fig. 1 Ventricular fibrillation (VF)

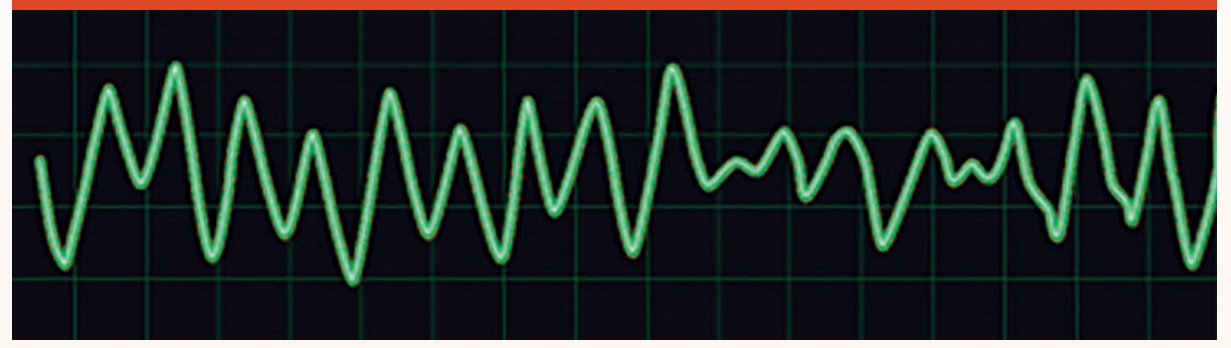

Fig. 2 Ventricular tachycardia (VT)

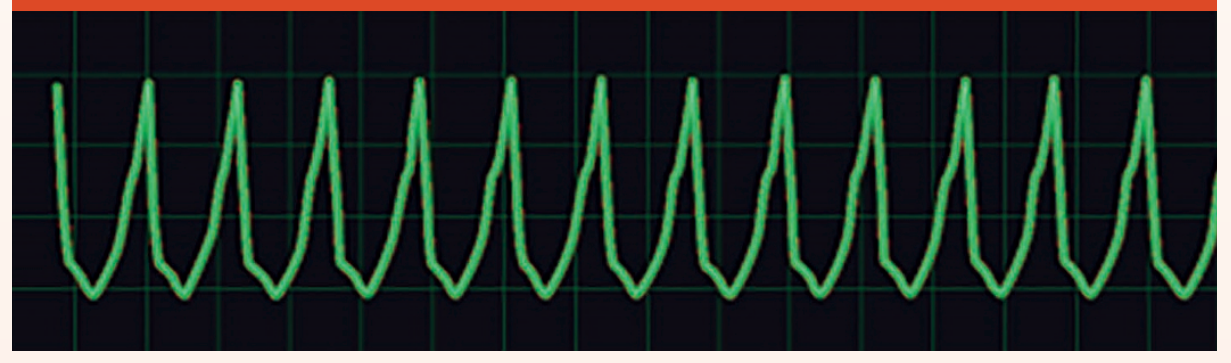

Fig. 3 Asystole - Flat-lining

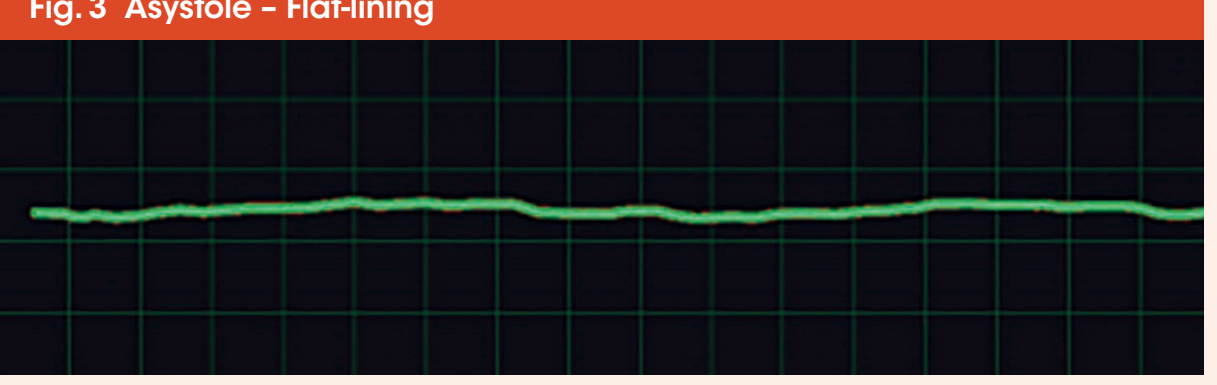

is unconscious and not breathing, you can use a defibrillator, which will stop the heart and hopefully restart it in a normal rhythm.

Asystole - Flat-lining (Figure 3) - This is too late for an automated external defibrillator (AED) in the community, as the heart has run out of oxygen and is now still.

\section{Your checklist}

- Danger - do not put yourself in danger

- Response - if no response, shout for help and if possible get a bystander to call for an ambulance and locate a defibrillator if there is one

- Airway - open the airway and check for breathing

- Breathing - If the casualty does not appear to be breathing normally and there are less than 2 breaths in a 10 second period you will need to start CPR

- If you are on your own - call 999/112 and get the AED as quickly as possible

- If you have help - the bystander will need to let the emergency services know that the casualty is unconscious and not breathing and bring the AED as quickly as possible. Continue CPR whilst waiting for the defibrillator.

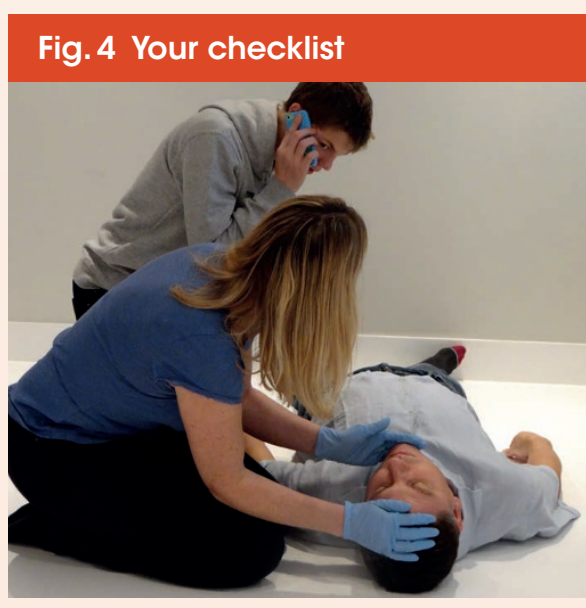

Fig. 5 When the AED arrives

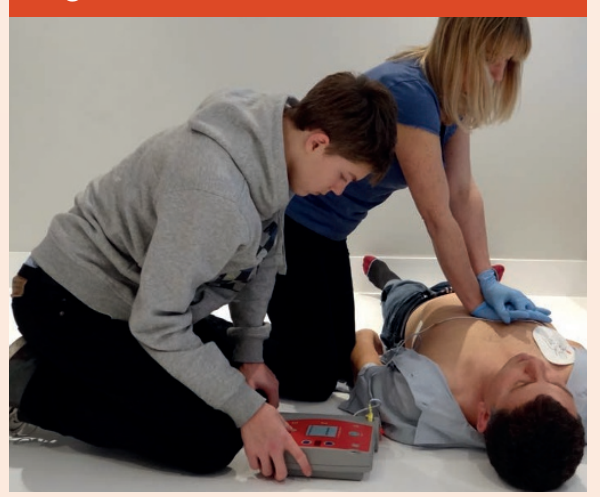




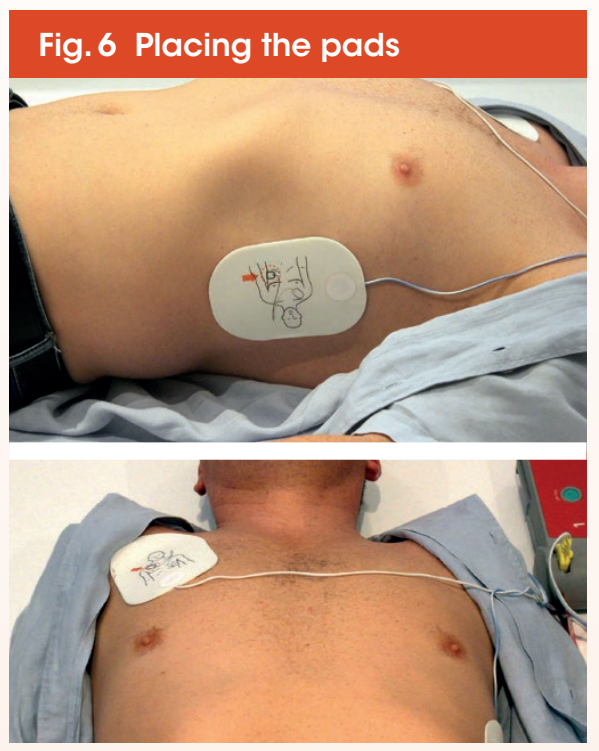

When the AED arrives

As soon as the AED arrives it should be activated (usually done just by opening the lid, or pressing an obvious button)(Figure 5). It will then start speaking to you. If there are two of you, one should continue with the CPR, whilst the other, attaches the leads to the AED (if necessary) dries the chest (and shaves them if necessary) and places the pads on the chest as per the diagrams (Figure 6).

- Peel the pad off the backing one at a time and place onto the dry chest according to the diagram.

- Place one pad below the casualty's right collar bone

- Place the other on the casualty's left hand side, over their lower ribs.

If you realise you have put the pads on the wrong way round - do not remove them as the AED will still work fine. If the AED offers a trace, this may appear upside down - but this will not affect the functioning of the AED.

- The AED will analyse the heart rhythm. Stop $\mathrm{CPR}$ when instructed and ensure no one is touching the casualty (Figure 7).

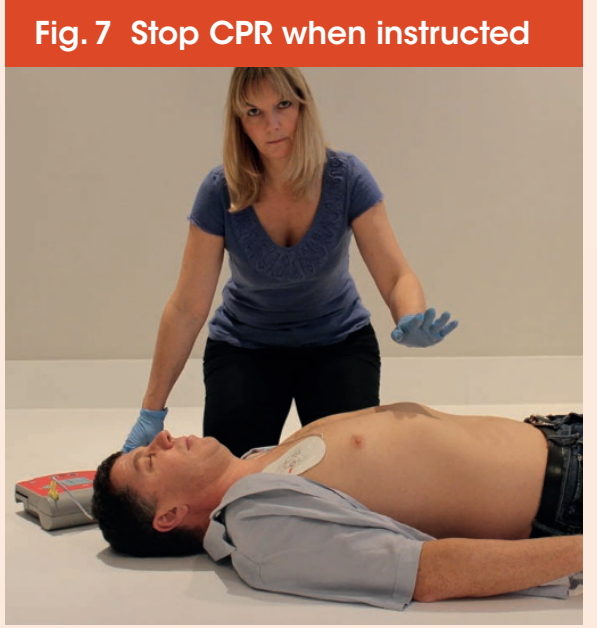

If a shock is advised:

- Check the whole length of the casualty to ensure no one is touching them. Loudly shout 'stand clear'

- Press the flashing shock button as directed (fully automated AEDs will do this automatically once a shock is advised)

- Continue with CPR as directed

- Keep going with 30 compressions to 2 breaths

Keep any time off the chest to an absolute minimum

- Do not stop to check them unless they begin to regain consciousness and start breathing normally

- The machine will reassess their heart rhythm every 2 minutes and advise another shock if indicated

If no shock is advised:

- Continue with CPR (Figure 8) and follow prompts

- Keep going until help arrives, you are too exhausted to continue, or the casualty begins to regain consciousness and starts to breathe normally

- The machine will reassess their heart rhythm every 2 minutes and advise a shock if indicated

- If there is more than one rescuer swap every couple of minutes

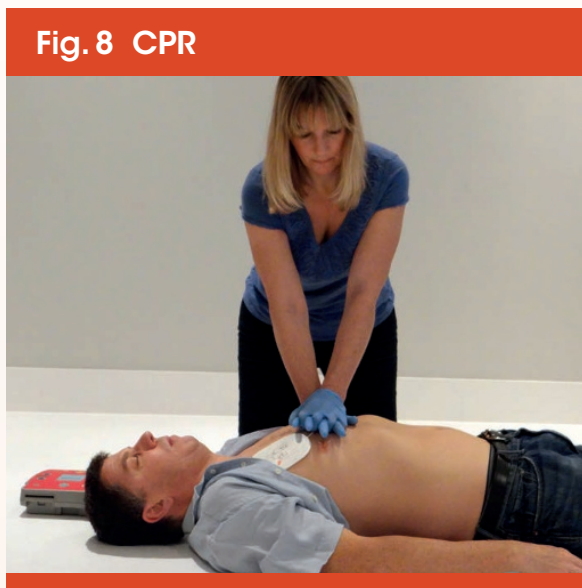

30 compressions

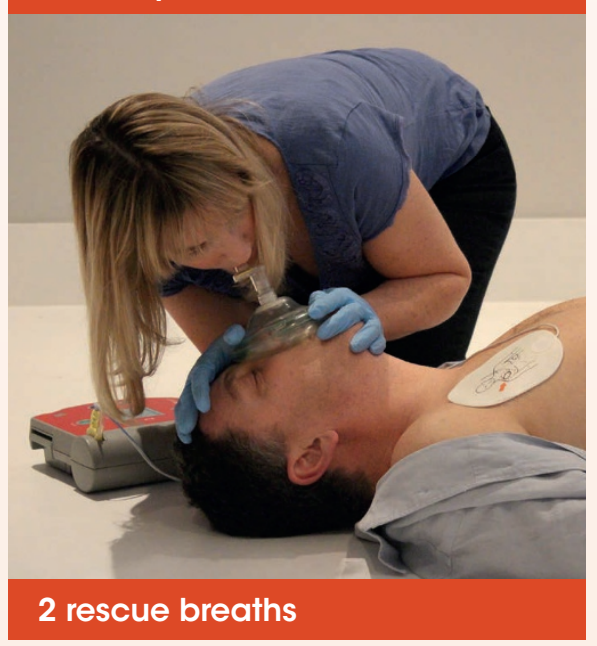

'DEFIBRILLATORS ARE ABSOLUTELY VITAL TO BE ABLE TO BRING SOMEONE BACK FOLLOWING A CARDIAC ARREST... IT IS THE AED THAT ENABLES THE HEART TO BE SHOCKED

\section{BACK INTO SINUS RHYTHM.'}

When the paramedics arrive The paramedics will need to know what happened, how long you have been doing CPR, whether a shock was advised by the AED and if so, how many shocks have been given (Figure 9).

Items to keep with your defibrillator

- Spare pads

- Paediatric pads

- Resuscitation mask

- Tough scissors to cut through clothes

- Gloves

- A towel

- A razor to remove excessive chest hair
Safety Considerations when using an AED (Figure 10)

- Electric Shock - The risk of electric shock from an AED is extremely small. Providing the chest is dry and the pads are well stuck, there is little chance of the charge arcing and causing a problem. However it is always sensible to check no one is touching the casualty when the shock is given

- Jewellery - avoid placing the pads over metal jewellery as it can conduct electricity and burn the casualty. Jewellery does not need to be removed

- Ensure the casualty is still when the AED is analysing the rhythm, to avoid 


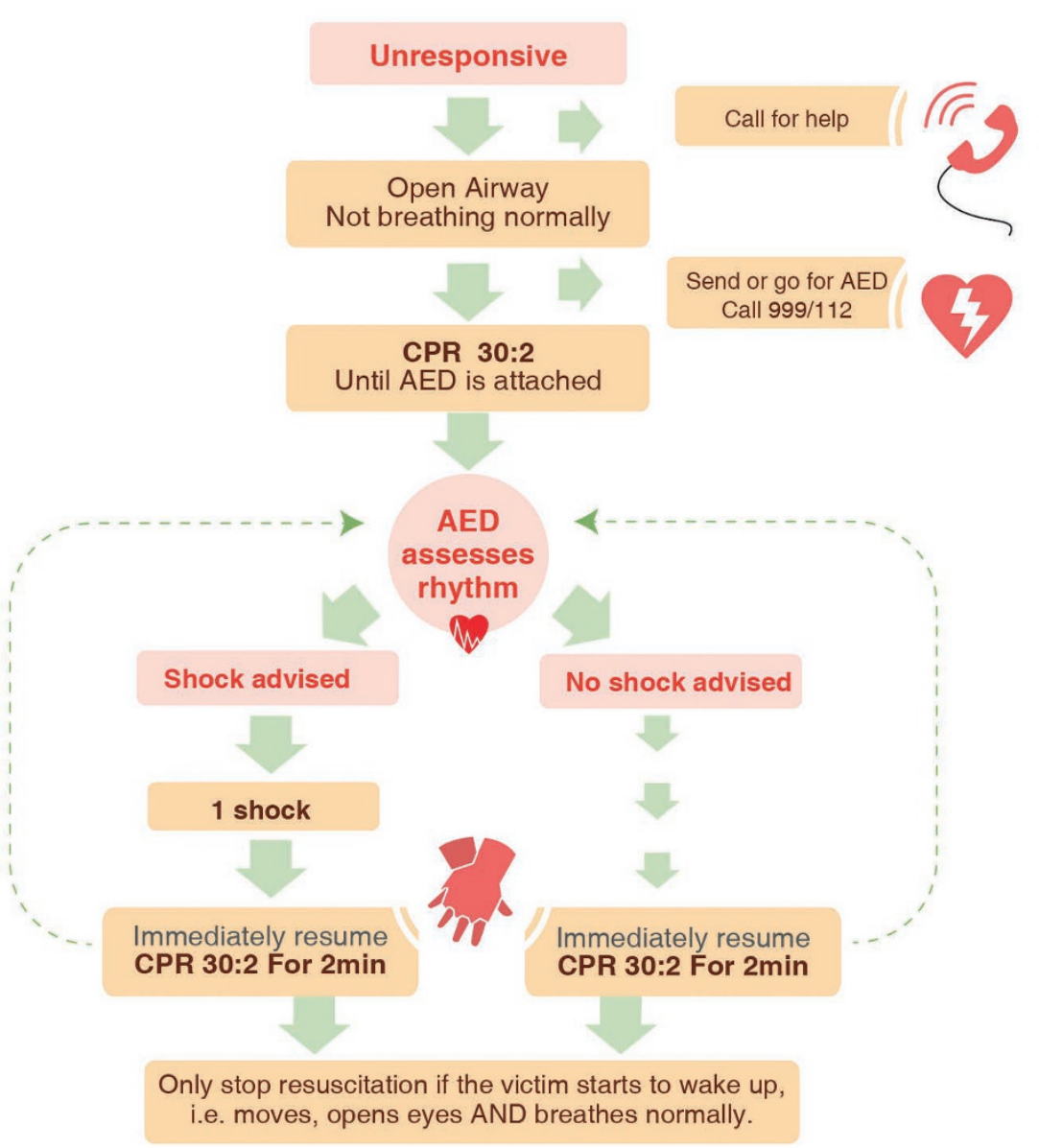

Fig. 10 Safety considerations when using an AED

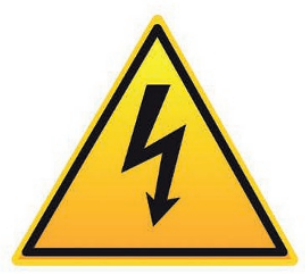

Electrical Shock

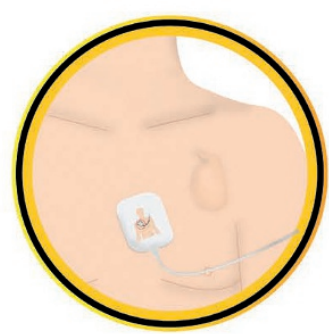

Don't place pads over implanted

devices or medication patches

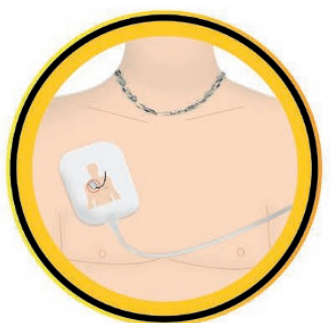

Avoid jewellery

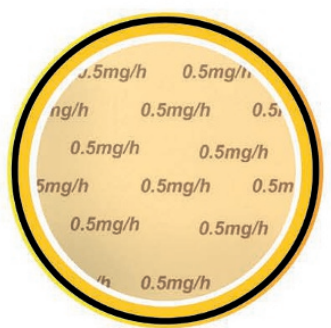

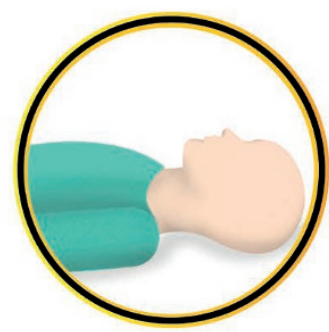

Ensure casualty is still

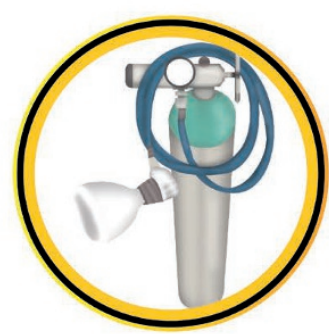

Flammable atmosphere - caution with Oxygen an inappropriate rhythm assessment. Switch off vehicle engines and vibrating machinery if possible

- Medication patches - Remove any obvious patches on the casualty's chest and do not place pads over them. Some heart patients wear GTN (glyceryl tri-nitrate) patches and these would explode if a shock was passed over them

- Implanted devices - most pacemakers are on the left hand side of the chest. Don't place pads over strange bumps or scars

- Flammable atmosphere - turn off oxygen when giving the shock, do not use in the presence of petrol fumes.

\section{Using a defibrillator on a child}

Some defibrillators have a switch or key that adapts it for child use. If you have a child over the age of 1 who needs a defibrillator, but only have adult pads available - adult pads can be used with one on the front of the child's chest and the other placed directly opposite, on the centre of their back. If it is a baby that needs resuscitating, you must use paediatric pads or the paediatric capability (Figure 11).

\section{AED signage}

All clinical dental areas should have immediate access (within the first minutes of a cardiorespiratory arrest) to oxygen, resuscitation equipment for airway management including suction, and an automated external defibrillator (AED). The standard AED sign (Figure 12) should be used in order to reduce delay in using a defibrillator in an emergency (www.resus.org. uk/defibrillators/standard-sign-for-aeds/).

\section{Maintenance of the AED}

Follow the manufacturer's recommendations for the maintenance of the AED. It should be kept in a prominent place and everyone in the building should have easy access to it and know where it is kept.

Check the expiry date for the battery and pads and order replacements in good time. Spare pads and a battery are highly recommended.

Most AEDs have warning lights and alarms to alert you if there is a malfunction or if the battery is running low. Some have a gauge that indicates battery charge. Ideally the AED should be briefly checked daily to ensure it is in good working order in case you need it. Most units have a battery life of around 5 years.

After the emergency - THE AFTERMATH

- Ensure appropriate paperwork and 


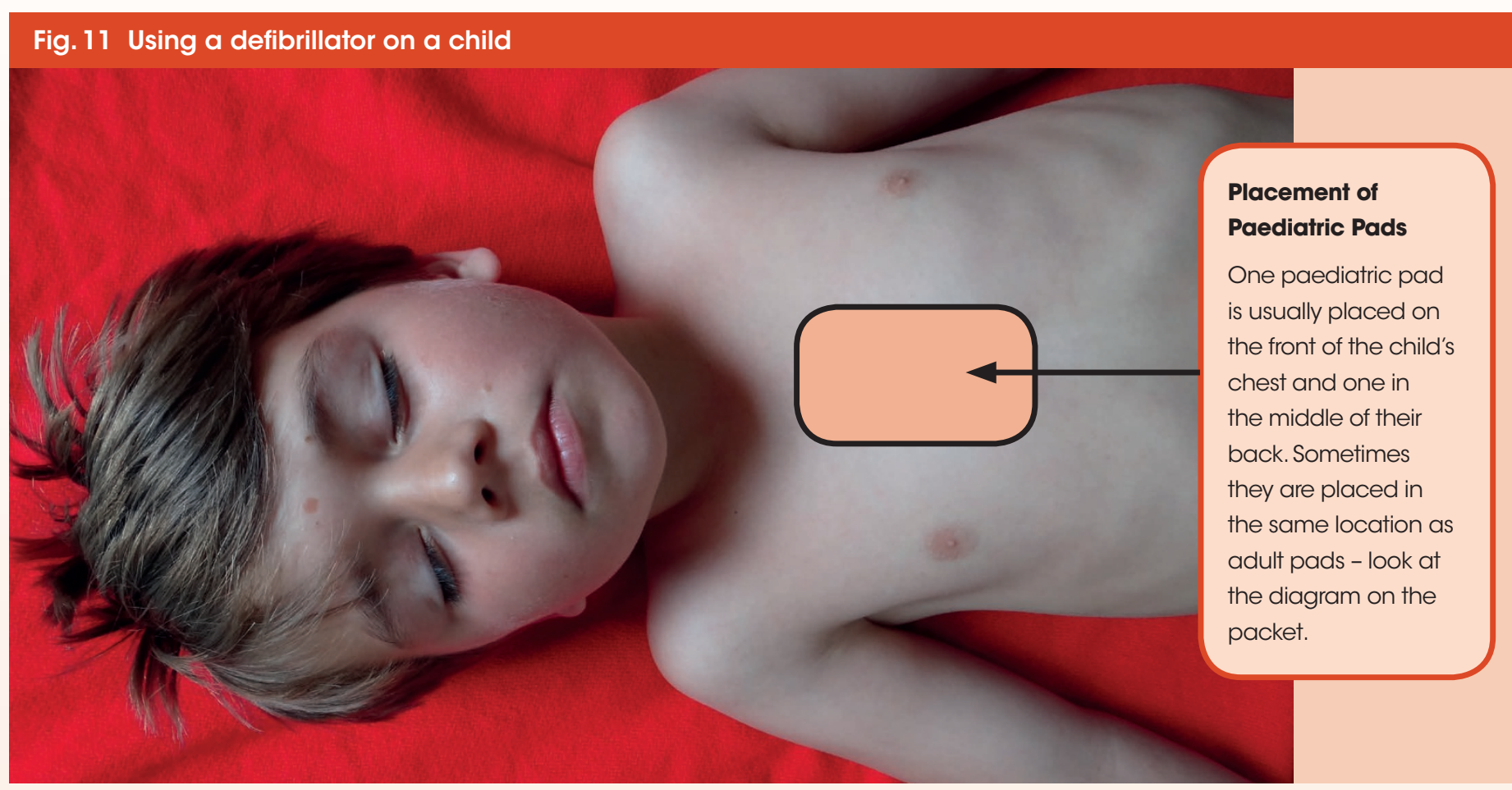

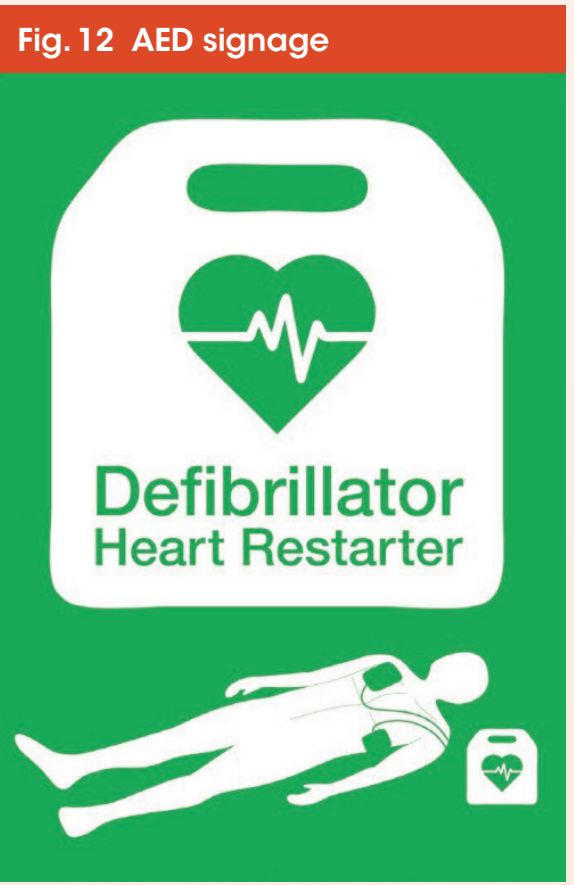

accident forms are completed and that there is a written log of all the emergency treatment and any drugs given (including oxygen)

- Restock anything that has been used

- Ensure that everyone is ok afterwards and make time to talk things through

- Dealing with a medical emergency can be extremely stressful and some people need professional help and counselling following such an episode. It is perfectly normal to feel any of the following;

a. A feeling of elation and an adrenaline buzz,

'THE SOONER YOU RECOGNISE THERE IS A

\section{PROBLEM, GET HELP ON THE WAY, START CPR,}

\section{USE A DEFIBRILLATOR AND THEN TRANSFER}

THE CASUALTY TO ADVANCED MEDICAL

$$
\text { CARE - THE BETTER THE OUTCOME.' }
$$
b. Anger
c. Confusion
d. Flashbacks and bad dreams
e. Depression.

Finally, the British Heart Foundation and Association of Ambulance Medical Directors in partnership with the University of Warwick have a national out-of-hospital database of community cardiac arrests and would welcome your input: https://warwick.ac.uk/ $\mathrm{fac} / \mathrm{sci} / \mathrm{med} /$ research/ctu/trials/ohcao/.

\section{References}

1. Valenzuela T D, Roe D J, Nichol G et al. Outcomes of rapid defibrillation by security officers after cardiac arrest in casinos. N Engl J Med 2000; 343: 12061209.

2. Jevon P. Medical emergencies in the dental practice. 2nd ed. Wiley: Oxford, 2013.
Emma Hammett is a qualified nurse and award-winning first aid trainer with over 30 years' healthcare and teaching experience. She is the Founder and CEO of First Aid for Life, a multi-award-winning, fully regulated first aid training provider specialising in first aid and medical emergency training for Dental Practices.

First Aid for life provides this information for guidance and it is not in any way a substitute for medical advice. First Aid for Life is not responsible or liable for any diagnosis made, or actions taken based on this information. 